\title{
O CUSTEIO-ALVO COMO SUPORTE ÀS DECISÕES PARA DESENVOLVER NOVOS PRODUTOS: UM ESTUDO EM INDÚSTRIA MOVELEIRA ${ }^{1}$
}

\section{COST-TARGETING AS SUPPORT FOR DECISION MAKING IN DEVELOPING NEW PRODUCTS: A STUDY IN THE FURNITURE INDUSTRY}

\author{
Romualdo Douglas Colauto \\ Doutorando em Engenharia de Produção \\ Universidade Federal de Santa Catarina - UFSC \\ Endereço: Rua XV de novembro, 150 - Apto 1307 - Edifício Alzemiro João Vieira - Campinas - São \\ José - Santa Catarina - Brasil - CEP 88101-440 \\ e-mail: rdcolauto@terra.com.br - Tel. (48) 1427542 \\ Ilse Maria Beuren \\ Doutora em Controladoria e Contabilidade FEA/USP \\ Professora do Programa de Pós-Graduação em Ciências Contábeis da Universidade Regional de \\ Blumenau (PPGCC - FURB) - Santa Catarina \\ Endereço: Rua Antonio da Veiga, 140 - Victor Konder - Blumenau - Santa Catarina - Brasil \\ CEP 89010-500- e-mail: ilse@ furb.br - Tel. (47) 3210565
}

\section{RESUMO}

O trabalho tem por objetivo apresentar a aplicação da metodologia do custeio-alvo como suporte à decisões de desenvolvimento de novos produtos em indústria moveleira. Os procedimentos metodológicos consistiram de uma pesquisa exploratória, realizada por meio de um estudo de caso, tendo uma empresa brasileira fabricante de móveis sob medida como sujeito da pesquisa. Assim, inicia-se com uma breve incursão nos aspectos conceituais do target costing, após contempla-se a abordagem da engenharia de valor, a seguir mostra-se a aplicação do custeio-alvo em uma indústria moveleira e apresenta-se as considerações finais do estudo. Os resultados da pesquisa evidenciam a viabilidade de aceitação de novo produto que atende às expectativas do cliente e ao mesmo tempo contemple o lucro operacional-meta estabelecido pela empresa.

Palavras-chave: Custeio-alvo. Desenvolvimento de novos produtos. Indústria moveleira.

\begin{abstract}
This work aims at presenting the application of cost-targeting methodology as a form of support for decisions regarding 4the development of new products in the furniture

\footnotetext{
${ }^{1}$ Trabalho Premiado no XI Congresso Brasileiro de Custos, realizado de 27 a 30 julho de 2004 - Porto Seguro BA.
} 
industry. The procedures undertaken included exploratory research in the form of a case study of a Brazilian bespoke furniture-making company. After a brief incursion into the concepts of cost targeting, an approach to value engineering is considered, followed by the application of the cost targeting in a furniture company with the study closing with the final considerations. The results of the research show the viability of the acceptability of a new product which meets the client's expectations and at the same time contemplates the operational-target gain as established by the company.

Key words: Cost-targeting; Development of new products; Furniture industry.

\section{CONSIDERAÇÕES INICIAIS}

O lucro é necessário para atrair capitais às empresas em funcionamento ou expansão. Portanto, os gestores devem buscar meios para obter lucro suficiente a fim de manter ou aumentar o valor de mercado dos investimentos dos acionistas (GRAY e JOHNSTON, 1977). Optar por investimentos em ambientes econômicos instáveis requer estudos preliminares para imergir em cenários de riscos. Nessa conjectura faz-se necessário selecionar ativos cuja expectativa é que venham a oferecer benefícios financeiros futuros compensadores, ou seja, que proporcionem um valor maior que o seu custo.

A evolução da gestão empresarial em busca de agregação de valor se estende por todo o meio econômico. A questão transcorre em como desenvolver produtos que fidelizem os clientes, ajudem a manter ou aumentar a competitividade e dêem lucro aos acionistas. Segundo Tucker (1999), essa evolução consubstancia-se, em essência, na mudança radical aa relação entre compradores e vendedores. Os compradores têm-se tornado cada vez mais exigentes e menos fiéis, recusando-se a pagar preços que trazem em seu bojo ineficiências e que estejam superavaliados. Questionam as imposições dos vendedores, preços, prazos e garantias, e substituem produtos consagrados no mercado por marcas semelhantes.

A contabilidade tem desempenhado papel relevante no processo decisório das organizações, buscando demonstrar através de um conjunto de informações, a situação patrimonial e econômico-financeira das mesmas. Arrigoni e Silva (1999) explicitam que as informações para tomada de decisões devem evidenciar os dois lados da realidade, dando ao gestor a possibilidade de perceber a dialética entre custos e receitas.

Em ambientes competitivos, em que o preço é determinado pelo mercado, o fator custo ganha destaque. Decorre-se que a lucratividade, bem como a continuidade do empreendimento, estão condicionados à eliminação ou pelo menos à redução dos custos que não adicionam 
valor. Por isso, conceitos e métodos como a target costing foram elevados ao nível estratégico, pois têm a ver com a própria continuidade do empreendimento. Até pouco tempo atrás, custo era, no Brasil, aquele valor a que se chegava, independentemente dos desperdícios e ineficiências, e sobre o qual se acrescentava uma margem de lucro (IUDÍCIBUS, 1995).

As dificuldades de ordem econômico-financeira contribuem para tornar o custo um tema relevante na gestão das organizações privadas e públicas. Em resposta às pressões ambientais, as empresas buscam os melhores instrumentos gerenciais para servir como suporte à tomada de decisões. Consideram que ao longo do tempo, os concorrentes conseguem igualarse à qualidade e ao preço do atual produto líder de mercado. Em resposta, emerge a importância de decisões adequadas para assegurar a eficiência e a eficácia empresarial.

Gestores descobriram que as vantagens competitivas residem na maneira como as atividades são executadas (HAMMER, 2001). Por conseguinte, o foco passa a ser a identificação de problemas e a eliminação de custos estruturais e operacionais que não agregam valor. Nesse aspecto, o comprometimento contínuo para redução dos desperdícios e a motivação constante dos gestores e empregados, para a diversificação do mix de produtos, devem ser metas de curto e longo prazo das organizações.

Uma forma de propiciar decisões acertadas é dotar os gestores de informações que contribuam para melhorar a performance decisória e reduzir os ricos inerentes. A identificação dos custos relevantes às decisões configura-se como importante parâmetro no processo informacional. A adoção de metodologias para conhecer o custo-alvo para estabelecer prioridades no planejamento estratégico e operacional é premente às organizações inseridas em ambientes competitivos.

O Target Costing é um sistema de planejamento de lucros e gerenciamento de custos, direcionado pelo preço, focado no consumidor, com projeto centralizado e multifuncional (ANSARI, 1997). A principal vantagem reside no planejamento dos custos, por meio da visão de mercado e redução de custos do produto, com ênfase orientada a partir de informações obtidas dos clientes. Caracteriza-se como uma metodologia de custeio com foco m mercado, considerando as necessidades do consumidor e a competitividade do mercado global (VIÉGAS e CALARGE, 2003).

De acordo com Cooper e Slagmulder (2000), o custeio-alvo possibilita as organizações administrarem estrategicamente os lucros futuros. Te m como princípio transformar o custo em um insumo do processo de desenvolvimento do produto e não em seu resultado. A empresa 
estabelece o custeio-alvo estimando o preço de venda de um produto planejado e subtraindo dele a margem de lucro desejada. O importante é projetar o produto de modo que satisfaça os clientes e possa ser fabricado dentro de um custo-alvo.

Nessa perspectiva, o artigo tem por objetivo mostrar a aplicação da metodologia do custeio-alvo como suporte às decisões para desenvolver novos produtos em indústria moveleira. Contempla-se, além das considerações iniciais, os procedimentos metodológicos da pesquisa, a abordagem conceitual do target costing, engenharia de valor. A seguir, mostra-se a aplicação do custeio-alvo em indústria moveleira e apresentam-se as considerações finais do estudo.

\section{PROCEDIMENTOS METODOLÓGICOS}

A pesquisa caracteriza-se como um estudo exploratório, utilizando-se de fontes secundárias, com abordagem lógica dedutiva. Tripodi, Fellin e Meyer (1981, p.64) explicam que o estudo exploratório tem por finalidade principal "desenvolver, esclarecer e modificar conceitos e idéias, a fim de fornecer hipóteses pesquisáveis para estudos posteriores”. Andrade (2002) elenca como finalidades substanciais para a pesquisa exploratória: a) proporcionar maiores informações sobre o assunto que se vai investigar; b) facilitar a delimitação do tema de pesquisa; c) orientar a fixação dos objetivos e a formulação das hipóteses; ou d) descobrir um novo tipo de enfoque sobre o assunto.

Quanto aos procedimentos sistemáticos para a descrição e explicação dos fenômenos, o estudo se desenvolveu num ambiente em que se preconizou a abordagem qualitativa. O método qualitativo, conforme Richardson (1999), caracteriza-se pelo não emprego de instrumental estatístico como base no processo de análise de um problema. Utilizourse a pesquisa bibliográfica para o desenvolvimento do trabalho, buscando formar um corpo teórico sobre o assunto proposto, e do estudo de caso, centrado em uma indústria moveleira.

A pesquisa bibliográfica busca, segundo Cervo e Bervian (1983), explicar um problema a partir de referenciais teóricos publicados em documentos, de forma a conhecer e analisar as contribuições culturais ou científicas passadas sobre um determinado assunto, tema ou problema. O estudo de caso, de acordo com Raupp e Beuren (2003), predomina nas pesquisas em que se deseja aprofundar conhecimentos a respeito de uma situação específica. Salientam que o pesquisador tem a oportunidade de verificar in loco os fenômenos a serem pesquisados. 
A escolha do sujeito da pesquisa foi intencional em função da acessibilidade aos dados. Trata-se de uma indústria de móveis sob medida, situada no Estado do Paraná. Quanto aos procedimentos de coleta de dados, optou-se por utilizar uma entrevista semi-estruturada com o sócio-proprietário da indústria, realizada em janeiro de 2004, para identificar os insumos necessários na produção de um móvel residencial e o critério utilizado para fixação do preço de venda.

O estudo não tem o compromisso de resolver os problemas acerca das decisões de investimentos no desenvolvimento de novos produtos, mas propiciar uma reflexão sobre a viabilidade da utilização da metodologia do custeio-alvo como instrumentos de suporte às decisões de investimentos para desenvolver novos produtos no setor moveleiro.

\section{ABORDAGEM CONCEITUAL DO TARGET COSTING}

O preço é apontado como um dos elementos importantes nas decisões de compra do consumidor e como diferencial competitivo para algumas organizações. Historicamente, o preço do produto era definido a partir dos custos de produção. Atualmente há uma preocupação por parte dos gestores em analisar a tendência do mercado na aceitação do preço do produto. De acordo com Pereira (2001), mesmo em mercados denominados monopolistas, os produtos concorrem com as alternativas que os consumidores dispõem para aplicação de seus recursos. Nesses mercados existe um preço máximo que o consumidor está disposto a pagar.

O Target Costing é um sistema direcionado ao mercado. A opinião do consumidor é um parâmetro para o desenvolvimento do processo de produção, para incorporar decisões de qualidade, custo e tempo na análise do custo de produção. Segundo Cooper e Slagmulder (2002), em mercados altamente competitivos, os clientes esperam que cada geração de produtos tenha um valor maior que as gerações anteriores. Este valor pode ser aumentado com a melhoria da qualidade, funcionalidade ou redução do preço de venda. Qualquer uma dessas melhorias ou a combinação de algumas delas requer que a empresa reduza os custo e mantenha o nível de lucratividade adequado à empresa (VIÉGAS e CALARGE, 2003).

O Target Cost (Custo-alvo ou Custo-meta) é entendido, tecnicamente, como o custo que se precisa atingir, na produção de determinado bem ou serviço, para garantir a obtenção de um preço que seja competitivo no mercado e que, ao mesmo tempo, propicie lucros justos à organização. A metodologia do Custeio-alvo, então, é o processo por meio do qual se chega a 
ele. Segundo Cooper (1997), com a utilização da técnica a empresa pode direcionar a estratégia de desenvolvimento de produtos e diminuir o risco com o lançamento desses novos produtos.

Viégas e Calarge (2003), ao fazerem referência à obra de Leahy (1998), The Target Costing Bull's Eye, expõem que a Segunda Guerra Mundial pode ser considerada um marco na história das organizações. Para atender as necessidades da Segunda Guerra, linhas de produção se proliferaram nas empresas bélicas. A General Eletric (GE), procurando reduzir seus custos para compensar a carência de materiais, na época criou a engenharia de valor. Por sua vez, as empresas japonesas adotaram a engenharia de valor e expandiram o conceito para criar o Target Costing. Sakurai (1997) explica que o custo-alvo foi desenvolvido no Japão, após o conceito e a prática foram levados à Alemanha e aos Estados Unidos, inicialmente utilizados em indústrias montadoras. Posteriormente, recebeu algumas modificações para se adaptar às indústrias de transformação e de computadores.

De acordo com Rocha (1999), os termos custo-alvo, custo-meta, custo-objetivo, ou outros equivalentes, são tão antigos quanto a necessidade de se ajustar o montante dos gastos ao da renda. Quanto a sua aplicação, afirma que trata-se de uma idéia aplicável à qualquer entidade econômica: empresas, instituições governamentais ou não, famílias, indivíduos etc. Porém, é no contexto do mundo dos negócios, em ambientes de acirrada competição, que o custeio-alvo ou target costing vem se revelando como um instrumento gerencial estratégico de grande importância aos gestores.

O custo- meta, segundo Atkinson et al. (2000), é o preço que os clientes estão dispostos a pagar por um produto, menos o lucro desejado. É o custo pelo qual um produto deve ser produzido, a longo prazo, para atingir a meta de rentabilidade, ou seja, o montante de custo em que a produção pode incorrer a fim de obter lucro para determinado produto. Para Sakurai (1997), custo meta é um processo de gerenciamento de custos para reduzir os custos totais, nos estágios de planejamento e desenho do produto. Atingir tais metas requer a concentração de esforços para integrar os departamentos de contabilidade, engenharia, produção e marketing.

O Custo-alvo pode ser entendido como o custo máximo admissível de um produto, com vistas a alcançar o nível de lucratividade desejada, considerando-se o preço de venda que o mercado suporta. Rocha (1999, p.126) menciona que o custo-alvo é considerado como o "montante de custos que deve ser eliminado ou aumentado para que o custo estimado de um produto ou serviço se ajuste ao admissível, tendo em vista o custo de uso e de propriedade para o consumidor, o preço-alvo e as margens objetivadas para cada elo da cadeia”. 
O custo-meta, segundo Maher (2001), representa uma abordagem sistemática para o estabelecimento do custo desejado de um produto. Com base no preço de venda aceitável, a companhia calcula o custo máximo que o produto deve ter, para que gere um lucro desejado. Pode-se inferir que um conceito mais amplo de custo-alvo envolve o custo de propriedade, onde se inclui não só o preço pago pelo cliente, mas também os custos de manutenção e descarte do produto.

O custo- meta toma o preço de venda como um parâmetro, baseando-se na premissa de que os clientes não estão interessados nos custos do fabricante. A partir dessa visão, a empresa deve gerenciar seus custos para que, no desenvolvimento e lançamento de novos produtos, possa praticar preços que lhe permitam alcançar a lucratividade desejada. O target costing é utilizado, sobretudo, para novos produtos, por isso, geralmente não há dados históricos nos quais padrões possam ser estabelecidos. O custo desejado, na realidade, funciona como uma meta, que a equipe de pesquisa e desenvolvimento, de desenho e produção procuram atingir. Caso o custo desejado não possa ser atingido, a administração deve repensar a viabilidade de lançamento do produto (MAHER, 2001).

Sakurai (1997) caracteriza o custeio-alvo como um instrumento de gerenciamento estratégico de custo, para alcançar a meta de lucro, especificada no planejamento empresarial a médio prazo. Explica que o custo-meta é uma parte do planejamento estratégico do lucro, isto é, considera que o plano estratégico das operações se encontra formulado levando em conta a concorrência e as necessidades dos clientes. Assim, integra as informações de marketing com fatores de engenharia e produção. Nos últimos anos da década de 80, conforme Rocha (1999), o custeio-alvo, como instrumento de gerenciamento de custos, vinculourse à estratégia empresarial no alcance do lucro alvo e manutenção da competitividade.

Entretanto, as razões de utilização do custo-meta diferem de uma organização para outra. A meta de uma empresa pode ser um processo fabril eficiente; um projeto de automação industrial, com ênfase na redução de custos na tentativa de majoração da lucratividade; produção com qualidade diferenciada do concorrente; desenvolvimento de novos produtos; criação de novas faixas de mercados; desenvolvimento de tendências. Sua importância está associada à redução do ciclo de vida dos produtos. Considera que este, ao se tornar mais curto, em função do consumidor exigir constantemente novos produtos, aumentou a importância e necessidade do gerenciamento dos custos nos estágios de planejamento e desenho, relacionados à engenharia de valor. 


\section{ENGENHARIA DE VALOR}

O custo-meta busca integrar toda a organização, envolvendo os talentos das pessoas, desde a fase de desenho e desenvolvimento do produto, até os serviços de pós-venda. Martins (2003) ressalta que a fase de planejamento é a responsável pela alteração substancial no custo do produto. Durante o projeto pode-se optar por alterar as características do produto na tentativa de reduzir custos, em detrimento da pré-disposição do mercado a pagar por esses bens e serviços, assim como, na quantidade absorvível pelo mercado consumidor. Explica que os esforços de redução de custos, na fase de projeto dos produtos, são efetivados por meio da engenharia de valor. Esta consiste na pesquisa sistemática de cada processo de elaboração do bem ou serviço, visando o aperfeiçoamento ao menor custo possível e, sobretudo, adequando os produtos às expectativas do mercado.

A engenharia de valor constitui a essência do custo-meta, compreendendo os esforços organizados no sentido de implementar análise funcional do produto para atingir, com maior grau de confiabilidade, todas as funções requeridas do ciclo de vida, ao menor custo possível. De acordo com Sakurai (1997, p.64), é vista como:

\footnotetext{
um método de manter pesquisa sistemática sobre cada função do produto ou serviço, a fim de se descobrir como atingir as funções necessárias com o menor custo total. Por outras palavras, é um método ou instrumento para praticar a reengenharia das funções ou finalidades de um produto ou serviço, a fim de aumentar sua qualidade ou valor, e conseguir a satisfação do cliente, ao menor custo.
}

Para Horngren, Foster e Datar (1997), a engenharia de valor é a avaliação sistemática de todos os aspectos das atividades da cadeia de valor, com o objetivo de simultaneamente reduzir custos e atender às necessidades do consumidor. A engenharia de valor proporciona melhorias no projeto dos produtos, alterações nas especificações dos materiais ou modificações nos métodos de processamento. Com a interação dos vários segmentos da organização, o setor de engenharia busca as melhores tecnologias disponíveis no mercado, quais componentes podem integrar o produto e quais podem ser excluídos.

Csillag (1995) expõe que na metodologia da engenharia de valor, o pessoal da mercadologia define os requisitos dos clientes, a engenharia define o produto, a manufatura define o processo de produção conforme as metas traçadas, além de outros especialistas, como compras, finanças e qualidade. Assim, todos os conhecimentos especializados e as habilidades disponíveis na organização são colocados ao alcance dos interessados, desde os estágios de 
requisitos de mercado até a assistência técnica. Com a participação dessas áreas do conhecimento melhora a comunicação e a compreensão dos inputs e outputs dos produtos.

Dessa forma, o setor de marketing analisa o comportamento do produto, delineado pela engenharia, por meio do levantamento das informações de preços, quantidades disponíveis de vendas, desejos e perspectivas dos consumidores. O setor de compras busca os fornecedores capazes de suprir as necessidades do processo produtivo, uma vez que estes são determinantes nos custos. A contabilidade, por sua vez, atua como órgão de suporte nas definições das estratégias financeiras, apuração de custos, elaboração de orçamentos e projeção das demonstrações contábeis. O envolvimento das diversas disciplinas traz um efeito sinérgico, cujo resultado é benéfico para a equipe (CSILLAG, 1995).

Sakurai (1997, p.49) mostra que a metodologia do custeio-alvo é contemplada como um "método abrangente de gerenciamento estratégico de custos que envolve a redução de custos durante todo o ciclo de sua ocorrência". Por conseqüência, o custo-meta exige a definição de uma estratégia empresarial, tanto no enfoque operacional, em termos de rentabilidade, considerando a análise de valor, quanto no estratégico, no que diz respeito ao melhor posicionamento de mercado, à continuidade do negócio e aos benefícios sociais gerados. Caso as atividades empresariais não sejam suficientes para gerar resultados que assegurem a reposição de seu capital investido no empreendimento, as mesmas estarão consumindo seu próprio potencial de geração de benefícios futuros. A persistência nessa condição acaba inviabilizando a continuidade do negócio no longo prazo.

A melhoria contínua do processo produtivo e a diversificação dos produtos, para satisfazer às ilimitadas necessidades dos consumidores, são vistas como uma estratégia essencial, para que as organizações mantenham-se competitivas no mercado global. Essa tendência, normalmente, gera maiores dispêndios que, por sua vez, incitam a complexidade dos métodos de direcionamento dos custos aos produtos. Como coadjuvante no processo de determinação do custo-meta, o custeio variável permite observar quais são os custos variáveis dos produtos e o volume de unidades necessárias para cobrir a estrutura de custos fixos das empresas, além de gerar resultados aos acionistas.

Entende-se que por meio do target costing a empresa identifica as necessidades dos clientes e verifica qual seria o preço de venda aceitável para um produto que satisfaça essas necessidades. Com base nesse preço de venda requerido pelo mercado, pode-se utilizar o Custeio Variável para identificar se a margem de contribuição total desses produtos é suficiente 
para absorver toda a estrutura fixa necessária para os novos produtos.

Segundo Maher (2001), o target costing utilizado nos lançamentos de novos produtos enfatiza, prioritariamente, a redução de custos nas fases de pesquisa, desenvolvimento, desenho e fabricação. Nesse aspecto, políticas de aperfeiçoamento contínuo do processo e administração das atividades são fundamentais para reduzir custos. Considera-se que a decisão de investimentos para lançamento de novos produtos requer uma análise acurada nos preços que os clientes estão dispostos a pagar. Com base nesses preços, pode-se, por meio do Custeio Variável, identificar a margem de contribuição individual por produto, em consonância à rentabilidade global objetivada pela empresa.

\section{DESCRIÇÃO E ANÁLISE DOS DADOS NA APLICAÇÃO DO CUSTEIO-ALVO EM INDÚSTRIA MOVELEIRA}

A empresa em que se realizou o estudo foi constituída em 1990. Caracteriza-se como empresa familiar, de pequeno porte, tributada com base no regime tributário Simples. É gerida pelos sócios-proprietários e tem como atividade a indústria de móveis residenciais e comerciais sob medida. Aufere um faturamento anual aproximado de um milhão de reais, possui aproximadamente vinte fornecedores e dez empregados. $\mathrm{O}$ foco da indústria está nos os clientes considerados classe A e B. Normalmente a indústria trabalha com vários itens diferentes e simultaneamente no processo de produção. No entanto, para efeito deste estudo, considera-se apenas um dos produtos, respeitando a capacidade instalada de fabricação.

O processo de fabricação de móveis sob encomenda envolve maior complexidade de gestão, tanto no que se refere ao controle dos custos de fabricação quanto à satisfação dos clientes. Uma das dificuldades na satisfação dos clientes exis te em função da customização dos produtos a fim de atender as particularidades de cada cliente. Nesta modalidade de produção, os marceneiros estão constantemente produzindo móveis em medidas e formas específicas, dificultando a padronização do processo de produção e incorrendo em maior probabilidade de re-trabalho. A determinação do custo real do produto requer controles específicos para cada modelo fabricado, de modo que a acuracidade dos custos pode ser comprometida em função da relação custo e benefício da informação.

Para o produto guarda-roupas de seis portas, nas dimensões de 2,40 metros de altura, 2,50 metros de largura e 0,52 metros de profundidade, em madeira marfim e verniz fosco, a 
capacidade total de produção da indústria limita-se a trinta unidades mensais. A determinação do preço de venda é efetuada com base na fórmula geral de fixação de preço de venda, acrescentando um markup de vinte e cinco por centro sobre os custos-base. No Quadro 1 apresenta-se a formação do preço de venda, bem como os insumos de produção estimados, divididos em custos variáveis unitários e custos fixos totais para a fabricação do produto.

\begin{tabular}{|l|r|l|r|}
\hline $\begin{array}{c}\text { Insumos de produção } \\
\text { variáveis unitários estimados }\end{array}$ & R\$ & \multicolumn{1}{c|}{$\begin{array}{c}\text { Insumos de produção fixos } \\
\text { mensais }\end{array}$} & R\$ \\
\hline Madeira em MDF & 410,00 & Projetos & $1.050,00$ \\
\hline Dobradiças & 90,00 & Controle processo produção & 800,00 \\
\hline Puxadores & 130,00 & Transporte & $3.000,00$ \\
\hline Mão-de-obra direta & 270,00 & Gastos administrativos & $5.000,00$ \\
\hline Materiais secundários & 24,00 & Gastos com vendas & $1.800,00$ \\
\hline Total & $\mathbf{9 2 4 , 0 0}$ & Total & $\mathbf{1 1 . 6 5 0 , 0 0}$ \\
\hline \multicolumn{2}{|r|}{} & Custos fixos unitário & $\mathbf{3 8 8 , 3 3}$ \\
\hline Custo unitário total do produto & $4.312,33$ \\
\hline Markup de margem de lucro de 25\% & $\mathbf{1 . 7 4 9 , 7 8}$ \\
\hline
\end{tabular}

Quadro 1 - Composição do preço de venda do produto

$\mathrm{O}$ custo pleno do produto equivale a $\mathrm{R} \$ 1.312,33$. Para determinação do custo fixo a indústria rateou-se o total de custos fixos pela capacidade instalada de produção de trinta unidades mensais. Ressalta-se que, de acordo com Horngren, Foster, Datar (2000), todos os custos fixos e variáveis são relevantes na determinação do custo alvo do produto. Explicam que, a longo prazo, os preços e as receitas devem cobrir todos os seus custos. Com relação a esta opção, tanto os custos fixos como os variáveis são relevantes para determinação do custo unitário total. O preço de venda é $\mathrm{R} \$ 1.749,48$ e, para chegar a este valor, a indústria acrescentou $\mathrm{R} \$ 437,44$ de margem de lucro operacional (25\% sobre os custos).

A indústria recebeu uma proposta de fabricação de trinta unidades de guarda-roupa nas especificações acima determinadas. A aceitação do pedido ocupará toda capacidade produção da indústria. O cliente não está disposto a pagar valor superior a $\mathrm{R} \$ 1.600,00$ por unidade. Supondo-se que não haja variações nos custos fixos e variáveis, no Quadro 2 mostra-se o custo alvo unitário e total da indústria em caso de aceitação da proposta para fabricar trinta unidades do produto guarda-roupas. 


\begin{tabular}{|l|r|l|c|}
\hline \multicolumn{1}{|c|}{ Formação custo alvo unitário } & \multicolumn{1}{c|}{$\mathbf{R} \$$} & \multicolumn{1}{c|}{ Formação custo alvo total } & \multicolumn{1}{c|}{ R\$ } \\
\hline Preço-meta de venda & $1.600,00$ & Receita-meta & $48.000,00$ \\
\hline (-) Margem de lucro operacional-meta & 437,44 & (-) Margem de lucro operacional-meta & $13.123,30$ \\
\hline (=) Custo máximo admissível & $1.162,56$ & (=) Custo máximo admissível & $34.876,80$ \\
\hline Custo variável & 924,00 & Custo variável & $27.720,00$ \\
\hline Custo fixo & 388,33 & Custo fixo & $11.650,00$ \\
\hline (-) Custo estimado & $1.312,33$ & (-) Custo estimado & $39.369,90$ \\
\hline (=) GAP (custo alvo) & $\mathbf{( 1 4 9 , 7 7 )}$ & (=) GAP (custo alvo) & $\mathbf{( 4 . 4 9 3 , 1 0})$ \\
\hline
\end{tabular}

Quadro 2 - Custo alvo unitário e total da indústria

A indústria está considerando o preço de venda de $\mathrm{R} \$ 1.600,00$, pré-determinado pelo cliente, como o preço-meta de venda. Assim, mantendo-se a margem de lucro operacional meta por unidade de $\mathrm{R} \$ 437,44$, o custo máximo admissível por unidade fabricada passa a ser de R \$ 1.162,56 (preço-meta de venda menos o lucro operacional-meta). Por essa metodologia, a empresa está diante de um GAP negativo de $\mathrm{R} \$ 149,77$ por unidade. Isto significa que a meta da indústria é buscar meios para reduzir o custo pleno de cada unidade fabricada em $\mathrm{R} \$ 149,77$ (custo alvo).

O custo máximo admissível reflete-se na posição competitiva empresa, porque é baseada em seus objetivos de lucro de longo prazo. Por isso, segundo Cooper e Slagmulder (2000), é preciso estabelecer metas de redução do custo-alvo de modo que seja atingível. Se a indústria estabelecer metas de redução do custo-alvo muito altas, submeterá os funcionários a elas, correndo o risco de exauri-los e ainda perder o rigor do custeio-alvo. Por outro lado, se estabelecer metas baixas, pode correr o risco de perder a competitividade.

Para reduzir as metas unitárias de custo e manter a margem de lucro operacional, a organização deve melhorar o processo de fabricação do produto. Esta melhoria pode ser obtida pelo envolvimento de todos os elos da cadeia de produção. A técnica de engenharia de valor envolve uma abordagem multidisciplinar do projeto do produto para maximizar o valor para o cliente, por meio da manutenção da qualidade e funcionalidade do produto e, ao mesmo tempo, reduzir os custos.

Por meio da engenharia de valor, a indústria trabalhou com equipes compostas pelo gerente de produção, o projetista, o gerente de marketing, o chefe de compras e o contador. Seguindo a premissa da engenharia de valor de distinguir os custos e atividades que adicionam valor e aqueles que não adicionam valor na perspectiva do consumidor, optou por fazer uma pesquisa de mercado para identificar os atributos considerados importantes no produto guardaroupa. No Quadro 3 mostra-se o índice relativo de importância atribuído por uma amostra de clientes. 


\begin{tabular}{|l|c|l|l|}
\hline \multicolumn{1}{|c|}{ Recursos } & $\begin{array}{c}\text { Grau de } \\
\text { importância }\end{array}$ & Índice relativo & \multicolumn{1}{|c|}{$\begin{array}{c}\text { Componente relacionado } \\
\text { ao produto }\end{array}$} \\
\hline Durabilidade & 5 & $33,34 \%$ & Madeira em MDF \\
\hline Qualidade dos puxadores & 2 & $13,34 \%$ & Puxadores \\
\hline Beleza do guarda-roupa & 3 & $20 \%$ & Verniz ou seladora \\
\hline Qualidade do acabamento & 4 & $26,66 \%$ & Mão-de-obra \\
\hline Qualidade das dobradiças & 1 & $6,66 \%$ & Dobradiças \\
\hline & 15 & $100 \%$ & \\
\hline
\end{tabular}

Quadro 3 - Índice relativo de importância atribuído pelos clientes do produto

O custo de valor adicionado representa o custo que o consumidor considera como adicionadores de valor ou utilidade (benefícios) ao produto. O percentual do índice relativo refere-se ao grau de importância atribuído pelos clientes, de acordo com cada componente utilizado no produto. O índice foi calculado de forma simplificada, ao considerar que a contribuição de cada componente está diretamente relacionada a apenas um atributo do produto. Assim, por exemplo, se a qualidade do acabamento estivesse associada, tanto ao componente mão-de-obra quanto ao verniz ou selador, haveria necessidade de apurar percentualmente a contribuição de cada um deles e associar o grau de importância dado pelo cliente para se chegar ao índice relativo.

Observa-se que os itens mais relevantes para os consumidores são a durabilidade e a qualidade do acabamento. A durabilidade está diretamente relacionada com a qualidade da madeira utilizada no processo de fabricação. A qualidade do acabamento está associada às atividades de lixar e pintar o móvel. Para a execução dessas atividades faz-se necessário que a empresa mantenha a qualidade dos materiais diretos. A solução utilizada foi contactar os fornecedores para negociar redução no preço do material direito, uma vez que poderá adquirilo em larga escala.

Com relação ao custo da mão-de-obra direta, o gerente de produção optou por negociar diretamente com os marceneiros. Utilizou como meios para ne gociação a oportunidade da empresa em utilizar toda sua capacidade de um único produto. $\mathrm{O}$ trabalho centrado em um modelo de móvel reduz o tempo de planejamento de execução do produto e, conseqüentemente, o marceneiro pode ganhar em termos de volume fabricado. O mesmo se aplica em relação à supervisão dos projetos e ao controle do processo de produção industrial.

A nova linha de fabricação implica na redução expressiva dos custos com projetos e fretes para entregas dos produtos. Pelas características da indústria, a cada cliente atendido é necessário um novo projeto de móvel, ou até vários projetos, para auxiliar na venda e execução. Na produção em série, este custo é reduzido pela simplificação do processo e 
desnecessidade de novos projetos a cada venda efetuada. Com relação aos custos de transporte, a indústria reduzirá a quilometragem rodada para entrega da produção. Além disso, poderá diminuir os custos com propaganda e publicidade, comissões sobre as vendas e despesas administrativas.

No Quadro 4 demonstra-se os insumos de produção variáveis e os custos e despesas fixos para a fabricação do produto, de acordo com o preço-meta de venda, após a utilização da engenharia de valor.

\begin{tabular}{|l|r|l|r|}
\hline \multicolumn{1}{|c|}{$\begin{array}{c}\text { Insumos de produção variáveis } \\
\text { unitário }\end{array}$} & R\$ & \multicolumn{1}{|c|}{$\begin{array}{c}\text { Insumos de produção fixos } \\
\text { mensais }\end{array}$} & R\$ \\
\hline Madeira em MDF & 410,00 & Projetos & 500,00 \\
\hline Dobradiças & 80,00 & Controle processo produção & 700,00 \\
\hline Puxadores & 130,00 & Transporte & $1.600,00$ \\
\hline Mão-de-obra direta & 250,00 & Gastos administrativos & $4.087,00$ \\
\hline Materiais secundários & 23,00 & Gastos com vendas & $1.200,00$ \\
\hline Total & $\mathbf{8 9 3 , 0 0}$ & Total & $\mathbf{8 . 0 8 7 , 0 0}$ \\
\hline \multicolumn{2}{|l|}{} & Custos fixos unitário & $\mathbf{2 6 9 , 5 7}$ \\
\hline Custo unitário total do produto & & $4.162,57$ \\
\hline Lucro operacional-meta previsto & $\mathbf{1 . 6 0 0 , 0 0}$ \\
\hline Preço-meta de venda do produto
\end{tabular}

Quadro 4 - Insumos para a fabricação do produto após a engenharia de valor

No Quadro 5 apresenta-se o resultado operacional-meta, considerando as metas de custos estabelecidos pelas equipes de gerência de produção, desenho do produto, gerência de marketing, compras e contabilidade. As estimativas iniciais de custos foram reconsideradas e adaptadas às especificações do produto, de maneira que a meta de lucro operacional, após a dedução dos insumos variáveis e dos custos e despesas fixas, fosse contemplada.

\begin{tabular}{|l|r|l|r|}
\hline Lucro operacional-meta unitário & \multicolumn{1}{|c|}{ R\$ } & \multicolumn{1}{|c|}{ Lucro operacional-meta total } & \multicolumn{1}{c|}{ R\$ } \\
\hline Receita Operacional-meta Bruta & $1.600,00$ & Receita Operacional-meta Bruta & $48.000,00$ \\
\hline (-) Custos diretos do produto & & (-) Custos diretos do produto & \\
\hline Custo da madeira em MDF & 410,00 & Custo da madeira em MDF & $12.300,00$ \\
\hline Custo das dobradiças & 80,00 & Custo das dobradiças & $2.400,00$ \\
\hline Custo dos puxadores & 130,00 & Custo dos puxadores & $3.900,00$ \\
\hline Custo da mão-de-obra direta & 250,00 & Custo da mão-de-obra direta & $7.500,00$ \\
\hline Custo com material secundário & 23,00 & Custo com material secundário & 690,00 \\
\hline (-) Custos e despesas operacionais & & (-) Custos e despesas operacionais & \\
\hline Projetos & 16,67 & Projetos & 500,00 \\
\hline Controle processo produção & 23,33 & Controle processo produção & 700,00 \\
\hline Transporte & 53,33 & Transporte & $1.600,00$ \\
\hline Administrativos & 136,23 & Gastos administrativos & $4.087,00$ \\
\hline Com vendas & 40,00 & Gastos com vendas & $1.200,00$ \\
\hline Custo pleno do produto & $\mathbf{1 . 1 6 2 , 5 6}$ & Custo pleno do produto & $\mathbf{3 8 . 4 3 7 , 0 0}$ \\
\hline Lucro operacional-meta do produto & $\mathbf{4 3 7 , 4 4}$ & Lucro operacional-meta do produto & $\mathbf{1 3 . 1 2 3 , 2 0}$ \\
\hline (=) Custo máximo admissível & $1.162,56$ & (=) Custo máximo admissível & $38.437,00$ \\
\hline GAP (custo-alvo) & $\mathbf{( 0 )}$ & GAP (custo-alvo) & $\mathbf{( 0 )}$ \\
\hline
\end{tabular}


Após o processo e engenharia de valor, o custo unitário pleno do guarda-roupa nas especificações e características definidas pelo cliente é equivalente a $\mathrm{R} \$ 1.162,56$. Este custo coaduna com o preço máximo suportado pelo cliente de $\mathrm{R} \$ 1.600,00$, além de possibilitar a margem de lucro operacional de 437,44 por unidade fabricada e vendida.

Deve-se ressaltar que, segundo Cooper e Sla gmulder (2000), a metodologia do custeioalvo não leva em conta as capacidades de redução de custos dos fornecedores e projetistas. Portanto, não há como assegurar de que a empresa atingirá o custo admissível. Assim, quando o custo admissível é considerado inatingível, a empresa precisa redefinir um custo mais alto no processo de custeio-alvo.

No processo de tomada decisões os gestores têm como objetivos básicos a maximização dos lucros, o aumento do valor de mercado das empresas e propiciar maiores retornos aos proprietários. De acordo com Pereira (2001, p.44), compete aos gestores fazer uso eficiente dos recursos para otimizar os resultados das atividades nas organizações. As atividades mantidas internamente devem ser competitivas, contribuindo favoravelmente para os resultados globais da empresa. Caso contrário, não se justifica mantê-las no ambiente interno da empresa, tendo em vista a existência de alternativas de mercado mais interessantes para a obtenção dos produtos gerados por essas atividades.

Martin (1999) menciona que a redução de custos deve começar com o entendimento de que os recursos mobilizados e utilizados por uma empresa têm o objetivo maior de produzir valor. Em toda a organização, efetua-se uma transformação produtiva, na qual os recursos são convertidos em bens e serviços para os quais há uma demanda. Essa transformação, cujo consumo de recursos gera, naturalmente, custos, deve produzir valor de duas naturezas distintas: a) valor para os clientes, que consiste nas características de desempenho e atributos que a empresa oferece na forma de bens e serviços, pelos quais os consumidores estão dispostos a pagar; e, b) valor para os investidores, buscando dar um retorno financeiro adequado aos recursos que aplicaram na empresa.

Ressalta-se que as empresas em geral não operam em ambientes monopolísticos. Isto significa que outras organizações também mobilizam e consomem recursos na tentativa de remunerar seus investimentos com maior eficácia. De acordo com Martin (1999), cada empresa fica submetida aos imperativos da competitividade, em função dos quais se vê forçada a encontrar constantemente meios mais eficientes de executar a transformação de recursos para 
sobrepujar seus concorrentes. Pode ser melhor sucedida aquela empresa que produzir aos clientes e investidores maiores retornos financeiros.

\section{CONSIDERAÇÕES FINAIS}

Investimentos em planejamento e desenvolvimento de novos processos e produtos ajudam a otimizar os custos. Além disso, contribuem para a concepção de produtos capazes de antecipar as expectativas dos clientes e, por sua vez, viabilizar melhores resultados à empresa. Essa preocupação está associada à continuidade normal do empreendimento, como organismo instituído para crescer, consolidar-se, atender aos objetivos estatutários, finalidades sociais e, por conseqüência, remunerar suficientemente o capital investido.

Os fatores considerados na tomada de decisões compreendem a realidade do ambiente econômico e as reais condições operacionais da organização. O modelo decisorial, embora possa variar em diferentes contextos, geralmente envolve a fixação de resultados esperados para o período de previsão, assim como para definição da taxa de atratividade do empreendimento. Mesmo que sejam razoavelmente quantificáveis os parâmetros para tomada de decisões, eles sempre constituirão aproximações da realidade, em função de certa subjetividade e arbítrio existente nos instrumentos utilizados para coletar, mensurar e processar os dados que suportam as decisões.

Em função da acirrada competição, os concorrentes conseguem, em maior ou menor tempo, igualar-se ou aproximar-se da qualidade e do preço dos produtos líderes de mercado. Lançar novos produtos para surpreender os clientes ou criar tendências exige vultosos investimentos em planejamento e pesquisas. Assim, há de se considerar a probabilidade desses investimentos nem sempre gerarem os benefícios futuros esperados pelos acionistas. Desse modo, faz-se necessário identificar, antecipadamente, qual é o preço dos produtos que pode ser suportado pelo mercado consumidor, como preconizado pela metodologia do Custeio-alvo.

No contexto em que os custos para a elaboração dos produtos têm como fator limitativo o preço de venda requerido pelos consumidores, considera-se apropriado utilizar os preceitos do custeio-alvo. O custeio-alvo pode ser utilizado como instrumento estratégico para administração dos custos, já no estágio de desenvolvimento do produto. A técnica considera que a possibilidade da organização modificar o produto no seu período de projeção aumenta significativamente o grau de redução dos custos. 
O objetivo do artigo consubstanciou-se em mostrar a aplicação do custeio-alvo em industria do setor moveleiro sob medida. Observou-se que, por meio da sinergia promovida pelos setores de marketing, compras, gerência de produção e contabilidade, a empresa conseguiu adequar o processo de fabricação de móvel para atender às expectativas do cliente e manter a margem de lucro-operacional meta estabelecida.

\section{REFERÊNCIAS}

ANDRADE, Maria Margarida de. Como preparar trabalhos para cursos de pós-graduação: noções práticas. 5. ed. São Paulo: Atlas, 2002.

ANSARI, Shahid L. et al. Target costing. Chicago: Irwin Professional Publishing, 1997.

ARRIGONI, José Fernando; SILVA, Rossália Maria de Souza. Modelo de decisões e importância no contexto do processo decisório. Faculdade de Economia, Administração e Contabilidade FEA-USP. Disponível em: <http://www2.usp.br/publishing/insite.cgi>. Acesso em: 12 maio 2003.

ATKINSON, Anthony A. et al. Contabilidade gerencial. São Paulo: Atlas, 2000.

CERVO, Amado Luiz; BERVIAN, Pedro Alcino. Metodologia científica: para uso dos estudantes universitários. São Paulo: McGraw-Hill do Brasil, 1983.

COOPER, Robin, Toyota Motor Corporation: Target costing system. Harvard Business School. n.9, p.197-231, May. 1997. Disponível em: 〈http://www.hbsp.harvard.edu/educators〉. Acesso em: 10 maio 2004.

COOPER, Robin; SLAGMULDER, Regine. Definir preço com rentabilidade. HSM Management. São Paulo, n. 18, p.86-94, jan./ fev. 2000.

CSILLAG, João Mario. Análise de valor. 4. ed. Atlas: São Paulo, 1995.

GRAY, Jack; JOHNSTON, Kenneth. Contabilidade e administração. São Paulo: McgrawHill do Brasil, 1977.

HAMMER, Michael. A agenda: o que as empresas precisam fazer para dominar esta década. Rio de Janeiro: Campus, 2001.

HORNGREN, Charles T.; FOSTER, George; DATAR, Srikant M. Contabilidade de custos. 9. ed. Rio de Janeiro: LTC, 1997.

IUDÍCIBUS, Sérgio de. A gestão estratégica de custos e a sua interface com a contabilidade gerencial e a teoria da contabilidade: uma análise sucinta. In: Congresso Internacional de Custos, IV, 1995. Campinas. Anais eletrônicos... Campinas-SP: UNICAMP, 1995. Disponível em: <http://libdigi.unicamp.br/document/list.php?tid=14>. Acesso em: 24 maio 2004. 
MAHER, Michael. Contabilidade de custos: criando valor para a administração. São Paulo: Atlas, 2001.

MARTIN, Nilton Cano. A redução estratégica de custos. Revista do Conselho Regional de Contabilidade de São Paulo. São Paulo, n.10, p.2-21, dez./ 1999.

MARTINS, Eliseu. Contabilidade de custos. 9. ed. São Paulo: Atlas, 2003.

PEREIRA, Carlos Alberto. Ambiente, empresa, gestão e eficácia. In: CATELLI, Armando. (Coord.). Controladoria: uma abordagem de gestão economia GECON. São Paulo: Atlas, 2001, p. 35-80.

RAUPP, Fabiano Maury; BEUREN, Ilse Maria. Metodologia da pesquisa aplicável às ciências sociais. In: BEUREN, Ilse Maria (Coord.) Como elaborar trabalhos monográficos em contabilidade: teoria e prática. São Paulo: Atlas, 2003, p.76-97.

RICHARDSON, Roberto Jarry et al. Pesquisa social: métodos e técnicas. 3. ed. São Paulo Atlas, 1999.

ROCHA, Welington. Contribuição ao estudo de um modelo conceitual de sistema de informação de gestão estratégica. 1999. Tese (Doutorado em Contabilidade e Controladoria). Faculdade de Economia, Administração e Contabilidade, Universidade de São Paulo, São Paulo, 1999.

SAKURAI, Michiharu. Gerenciamento integrado de custos. São Paulo: Atlas, 1997. TRIPODI, T; FELLIN, P.; MAYER, H. Análise da pesquisa social. Rio de Janeiro: Francisco Alves, 1981.

TUCKER, Robert B. Agregando valor ao negócio. São Paulo: Makron Books, 1999.

VIÉGAS, Paulo Eugênio Damasceno; CALARGE, Felipe Araújo. Uma proposta de formação do preço de venda utilizando os princípios do target costing. Simpósio de Engenharia de Produção, X, 2003. Bauru. Anais eletrônicos... Bauru-SP: UNESP, 2003. Disponível em: <http://www.simpep.feb.unesp.br/anais10/arq12.PDF>. Acesso em: 25 maio 2004. 